\title{
Characterization of genetic determinants of the resistance to phylloxera, Daktulosphaira vitifoliae, and the dagger nematode Xiphinema index from muscadine background
}

Bernadette Rubio ${ }^{1,2}$, Guillaume Lalanne-Tisné ${ }^{1,2}$, Roger Voisin³ ${ }^{3}$ Jean-Pascal Tandonnet ${ }^{1}$, Ulysse Portier ${ }^{3}$, Cyril Van Ghelder ${ }^{3}$, Maria Lafargue ${ }^{1}$, Jean-Pierre Petit ${ }^{1}$, Martine Donnart ${ }^{1}$, Benjamin Joubard ${ }^{4}$, Pierre-François Bert ${ }^{1}$, Daciana Papura ${ }^{4}$, Loïc Le Cunff ${ }^{2}$, Nathalie Ollat ${ }^{1 *}$ (D) and Daniel Esmenjaud ${ }^{3}$

\begin{abstract}
Background: Muscadine (Muscadinia rotundifolia) is known as a resistance source to many pests and diseases in grapevine. The genetics of its resistance to two major grapevine pests, the phylloxera $D$. vitifoliae and the dagger nematode $X$. index, vector of the Grapevine fanleaf virus (GFLV), was investigated in a backcross progeny between the F1 resistant hybrid material VRH8771 (Vitis-Muscadinia) derived from the muscadine R source 'NC184-4' and V. vinifera cv. 'Cabernet-Sauvignon' (CS).
\end{abstract}

Results: In this pseudo-testcross, parental maps were constructed using simple-sequence repeats markers and single nucleotide polymorphism markers from a GBS approach. For the VRH8771 map, 2271 SNP and 135 SSR markers were assembled, resulting in 19 linkage groups (LG) and an average distance between markers of $0.98 \mathrm{cM}$. Phylloxera resistance was assessed by monitoring root nodosity number in an in planta experiment and larval development in a root in vitro assay. Nematode resistance was studied using 10-12 month long tests for the selection of durable resistance and rating criteria based on nematode reproduction factor and gall index. A major QTL for phylloxera larval development, explaining more than $70 \%$ of the total variance and co-localizing with a QTL for nodosity number, was identified on LG 7 and designated RDV6. Additional QTLs were detected on LG 3 (RDV7) and LG 10 (RDV8), depending on the in planta or in vitro experiments, suggesting that various loci may influence or modulate nodosity formation and larval development. Using a Bulked Segregant Analysis approach and a proportion test, markers clustered in three regions on LG 9, LG 10 and LG 18 were shown to be associated to the nematode resistant phenotype. QTL analysis confirmed the results and QTLs were thus designated respectively XiR2, XiR3 and XiR4, although a LOD-score below the significant threshold value was obtained for the QTL on LG 18.

(Continued on next page)

\footnotetext{
* Correspondence: nathalie.ollat@inrae.fr

In memory of Dr Alain Bouquet

${ }^{1}$ INRAE, UMR EGFV, 33883 Villenave d'Ornon, France

Full list of author information is available at the end of the article
} 
(Continued from previous page)

Conclusions: Based on a high-resolution linkage map and a segregating grapevine backcross progeny, the first QTLS for resistance to $D$. vitifoliae and to $X$. index were identified from a muscadine source. All together these results open the way to the development of marker-assisted selection in grapevine rootstock breeding programs based on muscadine derived resistance to phylloxera and to $X$. index in order to delay GFLV transmission.

Keywords: Grapevine, Rootstock, Phylloxera, Nematode, Genetic architecture, Pest resistance, Muscadine

\section{Background}

Domesticated grapevine, Vitis vinifera sub-sp. vinifera [1], is grown grafted in most countries worldwide. Grafting has been successfully used to cope mainly with phylloxera (Daktulosphaira vitifoliae), an insect-pest that destroyed the European vineyard after its introduction from North America in the middle of the nineteenth century $[2,3]$ and participate to the control of other soil-borne pests and adaptation to abiotic stresses.

In addition to Europe, grapevine phylloxera spread quickly to most wine grape growing regions of the world including South Africa, Middle East, Asia and Australia [4]. This insect has two different forms, the radicicoles and the gallicoles, which affect roots and leaves, respectively. Radicicoles are the most destructive in $V$. vinifera due to severe root damage, while gallicole forms are more common in most other species without lethal effects for the plants. Root feeding induces the formation of galls called nodosities [4, 5]. Phylloxera root infection causes vine decline and finally plant death, partly explained by secondary fungal infections [2]. The use of resistant rootstocks from Vitis species other than $V$. vinifera is advocated as the main method of radicicole phylloxera management and may be considered as the most sustainable example of biological control for a pest ever used [6]. Several sources of grape phylloxera resistance for rootstock breeding have been identified. Heritability studies have shown that a variable number of loci control the resistance trait [7-11]. The first genetic mapping of a QTL for phylloxera resistance identified the RDV1 (RESISTANCE DAKTULOSPHAIRA VITIFOLIAE 1) locus on chromosome 13 in the Börner ( $V$. riparia $\times V$. cinerea) rootstock [12]. The RESISTANCE DAKTULOSPHAIRA VITIFOLIAE 2 (RDV2) locus was mapped to chromosome 14 in $V$. cinerea cv. 'C2-50' [5]. A leaf-specific phylloxera resistance locus overlapped the location of $R D V 2$ on LG 14 in a F1 family from a cross containing at least six Vitis species in the ancestry ( $V$. vinifera, $V$. riparia, $V$. rupestris, $V$. labrusca, $V$. aestivalis and $V$. berlandieri). In contrast, from the same plant material, a locus for resistance to the root form of phylloxera mapped to chromosomes 5 and 10 [13].

In addition to phylloxera, rootstocks may contribute to the control of other soil-borne pests such as root-knot and dagger nematodes. Resistance to the dagger nematode Xiphinema index is an important objective in grape rootstock breeding programs. $X$. index is a migratory ectoparasite that primarily feeds on the root tips of grapevines and causes severe damage to their root system. More significantly, $X$. index is recognized as the vector of Grapevine fanleaf virus (GFLV), the causal agent of the fanleaf degeneration disease which is considered to be one of the major threats to the grapevine industry $[14,15]$. $X$. index can survive in soils of ancient vineyards and retain GFLV for many years without the presence of host plant [16]. Nematicides and fumigants failed to control the dagger nematode because of their poor penetration in deep soil layers where $X$. index mainly survives $[17,18]$ and their use is now banned in most countries because of their high toxicity. In order to overcome these limitations, using nematode-resistant grapevine rootstocks appears as one of the most promising control method to significantly delay viral transmission. The highest level of resistance to $X$. index was found in $V$. arizonica, $V$. candicans, V. rufotomentosa, $V$. smalliana and $V$. solonis $[19,20]$. Resistance in $V$. arizonica is controlled by a single major locus, XIPHINEMA INDEX RESISTANCE 1 (XiR1) located on chromosome $19[21,22]$.

In the next decades, grape growing will have to face several challenges, such as climate change, decrease in pesticides application, water availability and competition for arable lands with food crops. In this context, it is important to consider the rootstock as a key component of adaptation and consequently, breeding new rootstocks is urgently needed. Rootstock breeding programs conducted throughout the world share similar goals, such as resistance to phylloxera and nematodes (dagger and root-knot nematodes), vigour management, mineral uptake efficiency, together with drought, salinity and limestone tolerances [20, 23]. The world's existing rootstocks have a very narrow genetic base derived from only a few American grape species accessions [24]. Despite the diversity available among the genus Vitis, only 4 to 5 species are commonly used in crosses, i.e. $V$. berlandieri, $V$. riparia, $V$. rupestris, $V$. champini and $V$. vinifera. Muscadinia rotundifolia, the muscadine vine, was also considered as a highly interesting species for rootstock improvement because of its resistance to 
many pests and diseases [10]. Thus, hybrids between this American species and $V$. vinifera were created in order to be used as rootstocks [25] or as parents or elite materials for further crosses [26]. However, muscadines present major defaults such as poor rooting, grafting incompatibility or mineral deficiencies, advanced crosses are necessary to breed highly and performing rootstocks.

Grapevine breeding takes generally decades to release an advanced cultivar. Considering the difficulty to screen for most traits of interest in rootstocks, the development of molecular-assisted selection is a priority. This relies on the identification of one or few loci closely associated to the trait expression and explaining a high percentage of phenotypic variance. As previously mentioned, only four loci have been identified so far in response to phylloxera in various Vitis species and a single one in response to $X$. index. Therefore it is crucial to improve our knowledge about the resistance response of Vitis and Muscadinia spp. resources to major grapevine pests and to analyse their genetic determinism. Recent progress in the development and application of molecular markers, genetic mapping and whole genome sequencing combined with high throughput technologies will help to better characterize the genetic bases of the traits of interest [27]. For grapevine, the development and application of SSR (Simple Sequence Repeat) markers are considered as a key step of the construction of molecular maps [21, 28, 29]. Next-generation sequencing (NGS) has then facilitated the development of methods to genotype very large numbers of SNP (Single Nucleotide Polymorphism) markers [30, 31]. Genotyping-by-sequencing (GBS) has been developed as a rapid and robust approach to sequencing of multiplexed samples [32, 33]. The work by Barba and collaborators [34] demonstrated the first application of the GBS procedure in generating SNPs to construct a high resolution map for QTL mapping in grapevine.

In order to identify additional sources of resistance to the phylloxera and to the dagger nematode, a backcross 1 ( $\mathrm{BC} 1)$ population from the cross between a muscadine hybrid (VRH8771 $=V$. vinifera $x M$. rotundifolia) and $V$. vinifera cv. 'Cabernet-Sauvignon' has been characterized in this study. Through this cross, one seeks to expand the existing knowledge about the genetic determinism of $M$. rotundifolia natural resistances towards the pathogens and pests. The main objectives of our study were i) to build SSR and SNP-based linkage maps using pseudo-testcross strategy and ii) to exploit them for QTL mapping of the genetic bases of the resistance responses to these major grapevine pests. These goals are the first steps toward the development of marker-assisted breeding for resistance to phylloxera and $X$. index.

\section{Results}

Genotyping: sequencing, SNP calling and SNP selection

A total of 84 million cleaned reads were obtained, and the number of reads per sample ranged from 36,000 to 9.5 million, with an average of 3.05 million. This number of reads was equivalent to $\sim 0.91$-fold coverage of other Vitis genomes which are estimated to have a size of approximately $500 \mathrm{Mb}$. The SNP calling performed with GATK pipeline and VCFtools produced a total of 324, 183 SNPs among which 52,625 have been identified as pseudotestcross markers. By excluding sites based on missing data or segregation distortion, two sets of 2285 and 738 SNPs were obtained for the female (VRH8771) and the male (CS) maps, respectively. These sets were complemented by 135 and 148 SSRs genotyped on 90 $\mathrm{BC} 1$ individuals for the construction of the female and male maps, respectively. Because of the missing data threshold per individual and the genotype frequencies expected, the final dataset included $92 \mathrm{BC} 1$ individuals. In the end, $75 \mathrm{BC} 1$ individuals were genotyped with both SSRs and SNPs markers, $19 \mathrm{BC} 1$ individuals with SNPs markers only and $17 \mathrm{BC} 1$ individuals with SSRs markers only (Table S1).

\section{High density maternal and paternal genetic maps} Maternal (VRH8771) and paternal (CS) maps were constructed using 2420 and 886 sets of markers (SSR and SNP markers), respectively (Fig. S1 and Fig. S2). For each set of markers, 19 LGs were produced and the final sizes for the VRH8771 and CS maps were 2351 and $1982 \mathrm{cM}$, respectively. The map density or average distance between markers for VRH8771 and CS maps was 0.98 and $2.24 \mathrm{cM}$, respectively (Table 1 ). The comparison of marker order with their physical position in VRH8771 and CS maps showed that most plots were on the diagonal or adjacent position (Fig. S3).

\section{Phenotypic evaluation of resistance to $D$. vitifoliae}

The phenotypic scores of phylloxera root resistance were obtained in both in planta and in vitro experiments using 89 and $37 \mathrm{BC} 1$ individuals, respectively. In the in planta experiment, results were expressed by a number of nodosities per plant whereas in the in vitro experiment they corresponded to a number of larvae counted on the five root pieces of each individual. A Spearman correlation between in vitro and in planta data was performed revealing a positive and significant correlation $(\mathrm{r}=0.47, p$-value $=0.003)$. Because of the effects of inoculation conditions, there was a large variability for nodosity and larvae numbers among the three replicates of each $\mathrm{BC} 1$ individual plant tested, as illustrated by an average value of 73 and $53 \%$ for the variation coefficients of in planta and in vitro experiments, respectively. Therefore, the maximal numbers of nodosities and 
Table 1 Characteristics of the maternal (VRH8771) and the paternal (V. vinifera cv. 'Cabernet-Sauvignon', CS) genetic maps of the BC 1 cross VRH8771 x CS

\begin{tabular}{|c|c|c|c|c|c|c|c|c|}
\hline \multirow{3}{*}{ Linkage Group } & \multicolumn{4}{|c|}{ Map of female parent VRH8771 } & \multicolumn{4}{|c|}{ Map of male parent CS } \\
\hline & \multicolumn{2}{|c|}{ Number of markers } & \multirow[t]{2}{*}{ Length (cM) } & \multirow[t]{2}{*}{ Average marker interval (cM) } & \multicolumn{2}{|c|}{ Number of markers } & \multirow[t]{2}{*}{ Length (cM) } & \multirow[t]{2}{*}{ Average marker interval (cM) } \\
\hline & SNPs & SSRs & & & SNPs & SSRs & & \\
\hline 1 & 68 & 9 & 90.36 & 1.17 & 46 & 7 & 123.13 & 2.32 \\
\hline 2 & 84 & 8 & 107.66 & 1.17 & 41 & 6 & 106.75 & 2.27 \\
\hline 3 & 140 & 8 & 117.91 & 0.80 & 21 & 9 & 96.94 & 3.23 \\
\hline 4 & 106 & 5 & 127 & 1.14 & 24 & 6 & 69.84 & 2.33 \\
\hline 5 & 176 & 7 & 173.84 & 0.95 & 67 & 7 & 115.5 & 1.56 \\
\hline 6 & 154 & 6 & 112.04 & 0.70 & 28 & 7 & 90.03 & 2.57 \\
\hline 7 & 47 & 7 & 87.7 & 1.62 & 36 & 10 & 121.33 & 2.64 \\
\hline 8 & 115 & 9 & 123.22 & 0.99 & 50 & 7 & 121.89 & 2.14 \\
\hline 9 & 120 & 7 & 119.21 & 0.94 & 25 & 7 & 73.25 & 2.29 \\
\hline 10 & 107 & 9 & 91.8 & 0.79 & 45 & 8 & 92.07 & 1.74 \\
\hline 11 & 120 & 4 & 121.07 & 0.98 & 42 & 6 & 92.56 & 1.93 \\
\hline 12 & 126 & 5 & 125.13 & 0.96 & 21 & 7 & 81.32 & 2.90 \\
\hline 13 & 108 & 7 & 212.89 & 1.85 & 42 & 7 & 98.58 & 2.01 \\
\hline 14 & 172 & 8 & 160.33 & 0.89 & 48 & 8 & 135.63 & 2.42 \\
\hline 15 & 17 & 5 & 57.74 & 2.62 & 14 & 7 & 107.16 & 5.10 \\
\hline 16 & 105 & 6 & 90.35 & 0.81 & 36 & 9 & 92.91 & 2.06 \\
\hline 17 & 158 & 6 & 154.09 & 0.94 & 63 & 10 & 96.87 & 1.33 \\
\hline 18 & 207 & 11 & 151.66 & 0.70 & 49 & 11 & 165.52 & 2.76 \\
\hline 19 & 141 & 8 & 126.69 & 0.85 & 40 & 9 & 101.18 & 2.06 \\
\hline TOTAL & 2271 & 135 & 2350.69 & 0.98 & 738 & 148 & 1982.46 & 2.24 \\
\hline
\end{tabular}

larvae per individual were confirmed to be reliable indicators of the quantitative resistance phenotype [12]. The negative control genotype, 'Börner', exhibited the expected results with a maximum number of 2 nodosities in planta and 9 larvae in vitro, respectively. Phenotypic responses of both parental genotypes were in agreement with what was expected, as VRH8771 resulted resistant and CS susceptible (Fig. 1). Over the population, the number of nodosities ranged from 0 to 37 (Fig. 1a) and the number of larvae ranged from 0 to 39 (Fig. 1b) in in planta and in vitro experiments, respectively. In both experiments, there were extensive variations of the phylloxera responses, with values of broad-sense heritabilities being 0.48 and 0.74 for nodosity and larvae numbers, respectively.

\section{Phenotypic evaluation of resistance to $X$. index}

In the first two experiments (2010-2011 and 2011-2012), resistance to $X$. index was screened from $35 \mathrm{BC} 1$ individuals, using roots characteristics (root development (RD) and root weight $(\mathrm{RW})$ ), the nematode reproduction factor $(\mathrm{RF})$ and the gall index (GI). The data obtained from these two experiments were analyzed together since no year effect was identified (Fig. S4 and Table S2). A principal component analysis (PCA) using those 35 individuals and the RD, RW, RF and GI criteria showed that the two first axes explained $94.25 \%$ of total variation (Fig. 2). Based on both the RF and GI criteria, resistant (R) and susceptible (S) groups were clearly identified. These two groups were separated along the first dimension of the PCA which is represented by these nematode development criteria. PCA demonstrated that susceptibility criteria vary independently from root characteristics. Statistical analyzes confirmed this result with significant differences in GI and
RF values between resistant and susceptible $\mathrm{BC} 1$ individuals (Wilcoxon signed-rank test $-p$-values of 0.00015 and 0.00013 for RF and GI, respectively). On the other hand, no statistically significant differences were revealed between resistant and susceptible $\mathrm{BC} 1$ individuals for the criteria (RD and RW) related to the roots characteristics (Wilcoxon signed-rank test $-p$-values of 0.335 and 0.535 for $\mathrm{RD}$ and $\mathrm{GW}$, respectively).

Spearman correlations were calculated among RD, RW, RF and GI criteria. There was no significant correlation between RD or RW on the one hand and RF or GI on the other hand, which confirmed the independence of the root and nematode developmental characteristics. The nematode reproduction factor (RF) was highly correlated with the gall index $(\mathrm{GI})(\mathrm{r}=0.59, p$-value $=$ 0.00019) (Table S3). Such a high significant correlation made it possible to rely on the gall index rating in order to score the response of the 60 total $\mathrm{BC} 1$ individuals to $X$. index within the independent experiments. An individual is classified as resistant when its replicates have a mean GI value lower than 1 and as susceptible when its replicates have a mean GI value equal or above 1 . Thus, on all five experiments, there were 50 and $10 \mathrm{BC} 1$ individuals characterized as resistant and susceptible, respectively. This segregation ratio 50R:10S fits the ratio of $7: 1\left(x^{2} 0.05=0.5978\right)$ expected when three dominant and independent genes control the resistance.

\section{Genetic determinism and mapping of the response to $D$. vitifoliae}

QTLs were detected for all traits scored and for their associated BLUP values in in planta and in vitro experiments. On the high-density genetic map of VRH8771 (Table 2), seven total QTLs were identified for both the 

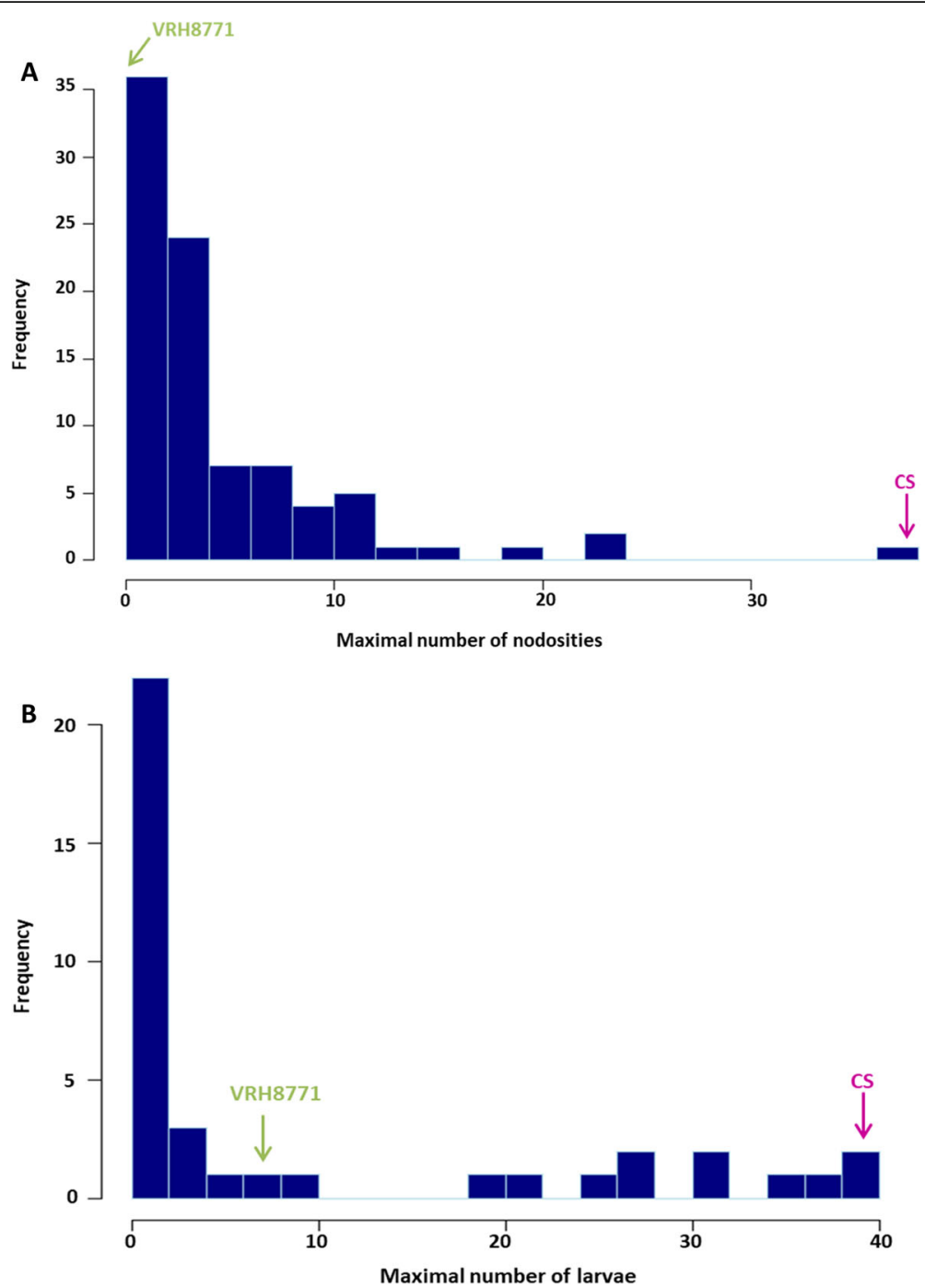

Fig. 1 Distribution of the $\mathrm{BC} 1$ individuals according to (a) the maximal number of nodosities (in planta experiment) and (b) the maximal number of larvae (in vitro experiment). Parental genotypes, VRH8771 and CS, are represented by a green and pink bar, respectively

maximum numbers of nodosities and the maximum numbers of larvae. These QTLs were localized on three LGs i.e. LG 3, LG 7 and LG 10. LOD scores and the explained phenotypic variances had higher values under in vitro conditions. This might be due to the lower environmental variations occurring under in vitro than under greenhouse conditions. On LG 7, several QTLs were found whatever the conditions and criteria within a confidence interval of $60 \mathrm{cM}$. In this group, the two QTLs detected for the criteria 'maximum number of nodosities' and 'BLUP nodosities' in in planta experiment explained each approximately $20 \%$ of the variability while the two QTLs detected in in vitro conditions for the criteria 'number of larvae' and 'BLUP larvae' explained variances of 87 and $70 \%$, respectively. Two QTLs were identified on LG 10 in in planta and in vitro experiments, respectively with the maximal number of nodosities and the BLUP values associated to the maximal number of larvae. Finally, analysis of BLUP values associated to the maximal number of nodosities in in planta conditions, showed a QTL on LG 3.

\section{Genetic determinism and mapping of the response to $X$. index}

The 7R:1S segregation ratio observed in our tests might suggest the presence of three dominant and independent resistance (R) factors controlling the response to $X$. index. With this hypothesis in mind for the detection of markers linked to resistance, we first used a method derived from the bulked-segregant analysis (BSA) [35]. As a double pseudo-testcross strategy was developed in the construction of the genetic maps, access to information on the different allelic forms was available only for SSR markers and, in a first step, the BSA-type analysis was 

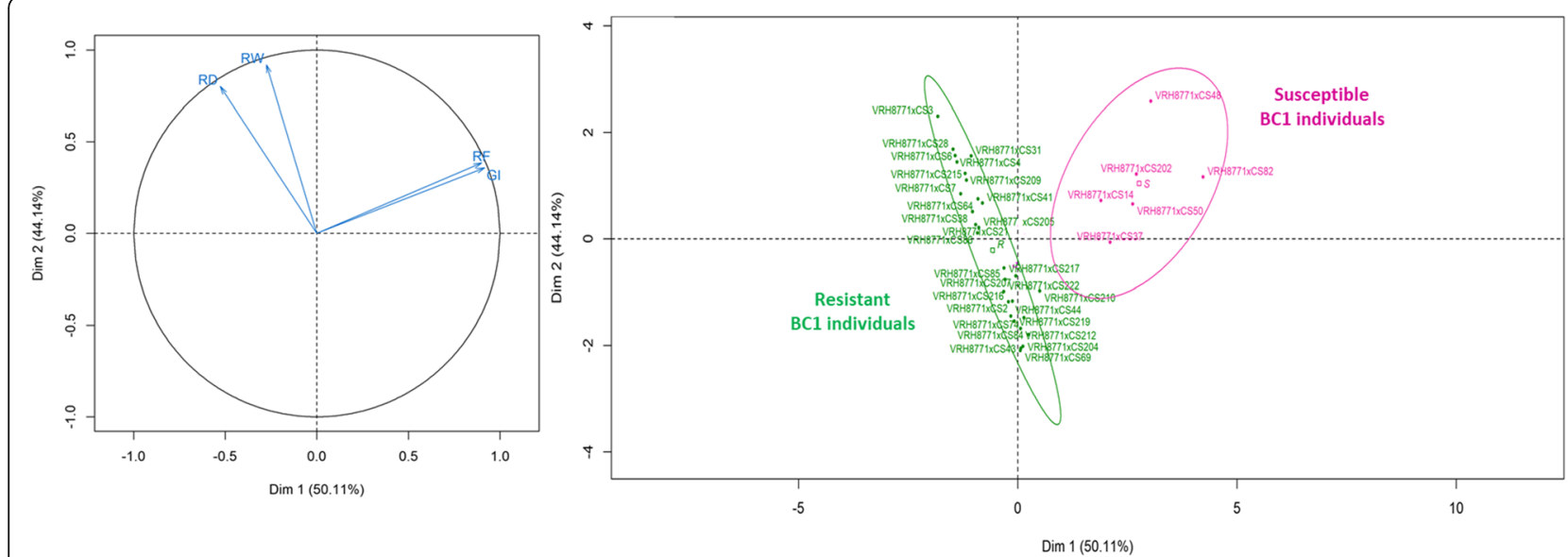

Fig. 2 Principal component analysis (PCA) of the 35 BC1 individuals tested in 2010-2011 and 2011-2012 experiments with root system development (RD), root weight (RW), nematode reproduction factor (RF) and gall index (GI). The two major principal components that accounted for $94.25 \%$ of the variance have been plotted. The rating criteria factor map (left) and the individuals factor map (right) are reported. In the individual factor map, the BC1 individuals were assigned to two distinct groups, the resistant group in green and the susceptible group in pink, based on their RF and Gl criteria

performed using only these markers. From the $2(\mathrm{ab}), 3$ (abc) or 4 (abcd) putative allelic forms of SSRs, we retained the markers for which an allele was detected in the resistant parent (VRH8771) and in a part of the resistant $\mathrm{BC} 1$ individuals but was lacking in all the susceptible $\mathrm{BC} 1$ individuals and the susceptible parent (CS). Markers meeting this requirement were located on the three linkage groups LG 9, LG 10 and LG 18 (Table 3), which is in line with the hypothesis of three dominant and independent $\mathrm{R}$ factors.

In order to use all the available genetic information related to the SSR and SNP markers, a proportion test was performed. This test aimed at comparing the proportion of resistant and susceptible individuals at each marker. Markers for which a statistically significant difference between resistant and susceptible proportions have been obtained, have been considered as potentially involved in the
$X$. index resistance response. Such groups of markers with significant differences in their $\mathrm{R} / \mathrm{S}$ proportions were found on LG 9, LG 10 and LG 18, corroborating the results obtained by BSA-type analyses from SSR markers (Table S4).

We finally performed a QTL analysis with a binary mapping model using the $\mathrm{R} / \mathrm{S}$ phenotypic information from $60 \mathrm{BC} 1$ individuals and the VRH8771 high-density genetic map. A first QTL explaining $22.73 \%$ of the phenotypic variance was detected on LG 9 with a LOD score of 3.66 (Table 4 - Fig. S5). VVBX-A-06, the marker identified at the QTL peak on this group, corresponds to the marker identified previously through both the BSA-type analysis (Table 4) and the proportion test (Table S4). A second QTL explaining approximatively the same proportion of phenotypic variance (21.19\%) was detected on LG 10 with an equivalent LOD score (3.59) (Fig. S5). The marker SC8-03 positioned at this QTL was the same as the

Table 2 Location and characteristics of the QTLs identified in in planta and in vitro experiments in response to D. vitifoliae

\begin{tabular}{|c|c|c|c|c|c|c|}
\hline Experiment & Trait & $\begin{array}{l}\text { Linkage group } \\
\text { (nearest marker) }\end{array}$ & LOD score & LOD threshold $=5 \%$ & $\begin{array}{c}\text { Confidence interval } \\
\text { (in cM) }\end{array}$ & $\begin{array}{c}\text { Total variance explained } \\
\text { by the QTL (\%) }\end{array}$ \\
\hline \multirow{2}{*}{ In planta } & Max. number of & 7 (VVIQ67) & 3.06 & \multirow{2}{*}{2.59} & $35-87.70$ & 19.02 \\
\hline & nodosities & 10 (VMC3D7) & 2.59 & & $0-63$ & 11.50 \\
\hline \multirow{2}{*}{ In planta } & \multirow{2}{*}{ BLUP nodosities } & 7 (VVIQ67) & 4.33 & \multirow{2}{*}{2.94} & $55-87.70$ & 20.13 \\
\hline & & $3\left(3 \_5494608\right)$ & 3.20 & & $27-117.91$ & 15.27 \\
\hline In vitro & Max. number of larvae & $7\left(7 \_4261424\right)$ & 4.31 & 3.25 & $22-87.70$ & 87.74 \\
\hline \multirow[t]{2}{*}{ In vitro } & \multirow{2}{*}{ BLUP larvae } & 7(7_13408919) & 10.93 & \multirow{2}{*}{3.44} & $29-77.16$ & 70.11 \\
\hline & & 10 (VVIN85) & 3.83 & & $29-50.21$ & 37.94 \\
\hline
\end{tabular}


Table 3 Distribution of the resistance alleles identified in the resistant parent VRH8771 using SSRs markers among resistant BC1 individuals in response to $X$. index

\begin{tabular}{ccc}
\hline $\begin{array}{c}\text { Linkage } \\
\text { Group }\end{array}$ & SSR Marker & $\begin{array}{c}\text { Number of the 47 resistant BC1 individuals displaying } \\
\text { the resistance allelic form at the marker }\end{array}$ \\
\hline 9 & VVBX-A-06 & 30 \\
& & \\
10 & MRBX-27 & 26 \\
10 & VVIN78-SEC & 26 \\
10 & VVIN85 & 26 \\
& & \\
18 & UDV-108 & 24 \\
\hline
\end{tabular}

marker detected by the proportion test on this linkage group but it was located distantly from the three SSR markers identified in the BSA-type analysis (MRBX-27, VVIN78-SEC and VVIN85). The third QTL with the highest LOD score (13.43\% of the total phenotypic variance) was located on LG 18, i.e. in the same third chromosomal location as in the BSA-type analysis and the proportion test. Marker UDV-108 identified at this QTL was also the marker obtained from both other analyses. Nevertheless, this later QTL had a LOD score of $\sim 2.5$ that did not reach the significant threshold value of 3.12 (Table 4). In descending order, other loci were detected on LG 7, LG 19 and LG 11 but with much lower values of LOD scores (2.0 to 1.5$)$ (Fig. 3).

\section{Discussion}

Genetic mapping of a $V$. vinifera $\times M$. rotundifolia cross

Vitis $x$ Muscadinia crosses have a very low fertility due to the differences in chromosome number that generate an incomplete homology between the genomes at meiosis [21]. Despite this limiting factor, a few F1 hybrids were obtained and have then been successfully backcrossed with Vitis species. Although the size of the progeny was limited, QTL analyses are reliable at the sight of the reproducibility of results obtained through different experimental conditions (in planta and in vitro) and different statistical methods (in silico BSA and QTL detection). This paper first reports the construction of high-density grapevine genetic maps for the $\mathrm{BC} 1$ progeny involving the $V$. vinifera $x M$. rotundifolia accession 'VRH8771' and the $V$. vinifera cv. 'Cabernet-Sauvignon' using both SSR and SNP types of markers. The framework maps established using SSR markers from other grapevine crosses were completed with SNP markers generated by GBS [28, 29, 34, 36, 37]. Among the whole genome and next generation sequencing techniques, GBS offers an inexpensive and robust solution for simultaneous SNP discovery and genotyping [32, 33]. In grapevine, GBS has already been used in the construction of high-resolution maps for the detection of QTLs linked to powdery and downy mildew resistance $[34,38,39]$. In the present map, the number of SNP markers was lower in the paternal parent, CS, than in the maternal parent, VRH8771. This difference is linked to the use of the $V$. vinifera CV. 'Pinot Noir' (PN40024) reference genome in our analyses [40, 41]. Actually, this genome is genetically closer to CS than to the Vitis $x$ Muscadinia hybrid VRH8771, which explains a higher number of polymorphic markers in the maternal accession [42]. As already shown in other studies, the comparison of the marker order with their physical position in VRH8771 map confirmed the high level of macrosynteny between the $V$. vinifera and $M$. rotundifolia genomes [21, 42, 43]. The average distance between adjacent markers in all linkage groups in the maternal map was $0.98 \mathrm{cM}$, which is the same range of density reported by Teh et al. [39] and Sapkota et al. [38]. The saturation level of the maternal genetic map is close to the

Table 4 QTLs identified using a binary model in response to $X$. index performed on 60 BC1 individuals

\begin{tabular}{cccccc}
\hline $\begin{array}{c}\text { Linkage group } \\
\text { (nearest marker) }\end{array}$ & LOD score & $\begin{array}{c}\text { LOD threshold } \\
\mathbf{5} \mathbf{5 \%}\end{array}$ & $\begin{array}{c}\text { LOD threshold }= \\
\mathbf{1 0 \%}\end{array}$ & $\begin{array}{c}\text { Confidence interval (in } \\
\text { cM) }\end{array}$ & $\begin{array}{c}\text { Total variance explained } \\
\text { by the QTL (\%) }\end{array}$ \\
\hline 9 (VVBX-A-06) & 3.658 & 3.12 & 2.94 & $28.99-52.19$ & 22.73 \\
$10(\mathrm{SC}-03)$ & 3.592 & 3.12 & 2.94 & $41.79-91.80$ & 21.19 \\
& & & & \\
18 (UDV-108) & 2.499 & 3.12 & 2.94 & $133.27-151.66$ & 13.43 \\
\hline
\end{tabular}




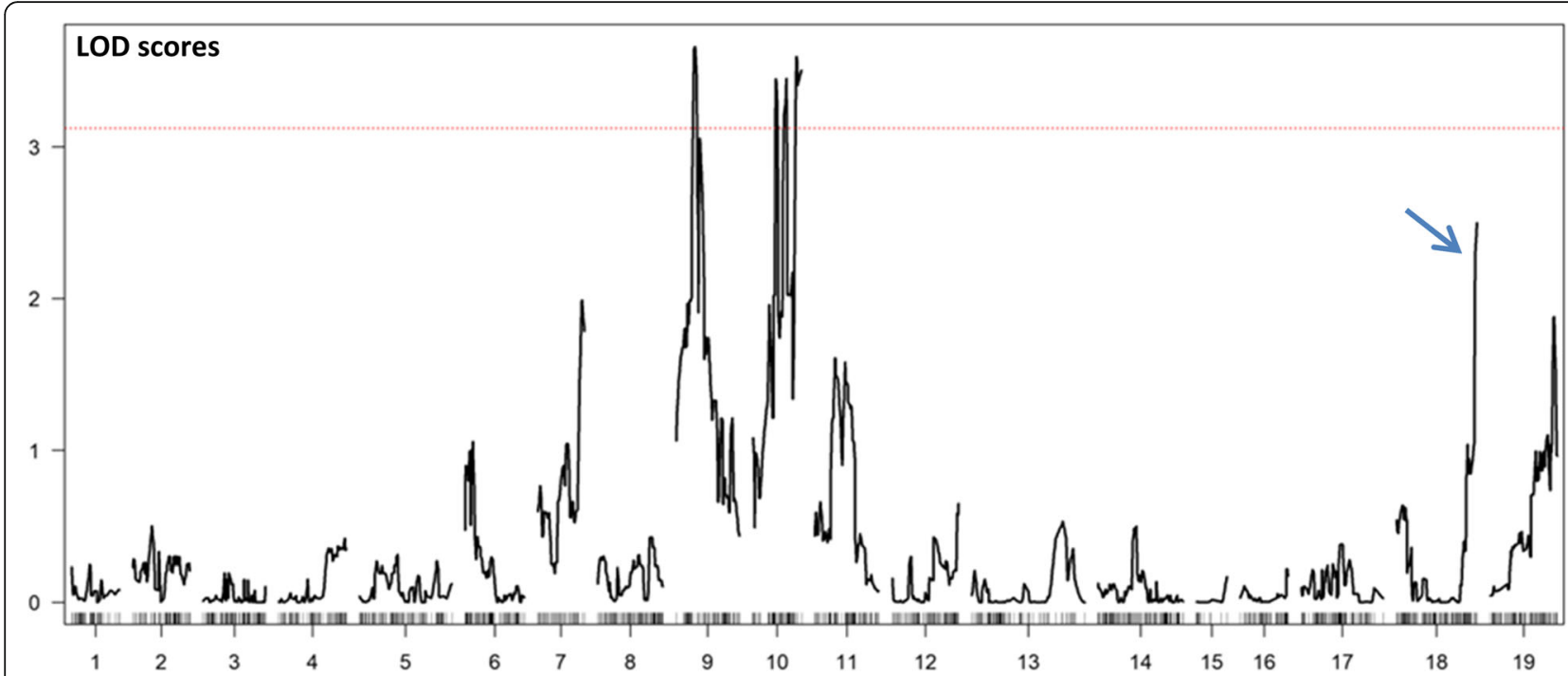

Fig. 3 QTL analysis of the resistance to $X$. index performed on $60 \mathrm{BC} 1$ individuals. The $y$-axis represents the LOD score obtained by the binary mapping and the $x$-axis represents the 19 linkage groups related to the maternal genetic map (VRH8771). Curves in plot indicate the genetic coordinate (x-axis) and LOD score (y-axis). The red dotted line represents the LOD significant threshold estimated with 1000 permutations for a level a of 0.05 . The blue arrow corresponds to the genomic region below the significant threshold but with a high LOD score value

map established by Delame et al. [42] for a muscadine derived progeny.

\section{Identification of original QTLs for nodosity formation and larval development in response to root infection by $D$. vitifoliae}

The response of the $\mathrm{BC} 1$ plants to phylloxera has been explored through both in vitro and in planta experiments. As expected in each experiment a wide variability of the response has been observed among replicates of a same plant individual due in particular to the vigour of the insect population. To minimize this effect, we considered the maximal values of the criteria studied as the most reliable indicators of the quantitative resistance phenotype [12]. Moreover, a linear mixed model was used to access the block effect in relation to the experimental design in randomized blocks. Thus, BLUP values were estimated and accounted for environmental effects [44]. This method has been used to optimize the statistical power for the detection of significant QTLs [45, 46]. A QTL was detected on LG 7 for nodosity and larvae numbers with an explained phenotypic variance that reached $87 \%$ in the in vitro experiment. The physiological status of the roots (which insects fed from) in each experiment, i.e. either connected to their plant (in planta) or completely detached from it (in vitro), was quite different. Despite this, the strongest QTLs in both experimental conditions were located on the same chromosome (LG 7). Such results are in agreement with those obtained by Bouquet [10] who reported also a good correlation of the data between the experiments conducted in vitro and in the greenhouse and/or the vineyard. Moreover, this author recorded a low ratio of phylloxera resistant plants in such $V$. vinifera $\mathrm{x} M$. rotundifolia $\mathrm{BC} 1$ progenies. He suggested that this low ratio can be explained if the $\mathrm{R}$ factor controlling this trait is carried by a Muscadinia chromosome which has a low probability of pairing with its homologous $V$. vinifera chromosome in the F1 hybrids. By locating our major QTL in LG 7, the Vitis chromosome which had been split into the LG 7 (upper arm) and LG 20 (lower arm) in Muscadinia, our current data are in line with this previous hypothesis of a location of this $\mathrm{R}$ factor in the lower arm of chromosome 7.

Nevertheless, two other QTLs were also identified on LG 3 and LG 10 in our results, suggesting that other loci may influence or modulate nodosity formation and larval development.

The putative involvement of several QTLs in response to phylloxera has already been reported in the literature. Davidis and Olmo [8] first hypothesized that the resistance from a $M$. rotundifolia accession was controlled by more than one locus. Then Bouquet [10] suggested that grape phylloxera resistance in $M$. rotundifolia might be mediated by a semi-dominant locus regulated by three genetic modifiers. Similarly, in interspecific crosses involving different American Vitis species (V. berlandieri, $V$. cinerea and $V$. rubra) and $M$. rotundifolia, Boubals [7] concluded that the resistance appears to be controlled by multiple loci. Four root grape phylloxera resistance QTLs have already been identified in Vitis spp. In $V$. cinerea, two QTLs have been mapped in two 
different accessions: RDV1 located on LG 13 in cv. 'Arnold' [12] and RDV2 located on LG 14 in cv. 'C2-50' [5]. Two other QTLs have been detected on LG 5 and LG 10 in an F1 cross containing at least six Vitis species in the ancestry [13]. In our study, three new QTLs were identified from $M$. rotundifolia background. Interestingly, these seven QTLs have been mapped on six different LGs. The news QTLs were officially named $R D V 6$, $R D V 7, R D V 8$, according to their position on LG7, LG3 and LG10 respectively.

\section{Resistance response to the dagger nematode $X$. index maps on three different LGs}

The individuals were tested for their response to the dagger nematode $X$. index among successive experiments and no significant differences were found between the years of experiment, which underlines the reproducibility of the experimental protocol and the reliability of phenotyping.

Our evaluation of $X$. index resistance used a nematode reproduction factor and a root gall index assessed 10 to 12 months after inoculation. The root weight and a visual index of root development were also considered in order to study their relationships with the nematode development criteria previously mentioned. Gall index was shown to be highly correlated with the nematode reproduction factor but not with root characteristics. Such gall index rating method has been previously used in a genetic study for resistance to $X$. index in $V$. arizonica. It allowed the characterization of the early resistance conferred by the locus XiR1 4 to 8 weeks after inoculation in a fast greenhouse-based screening system $[22,47]$. Our current data demonstrate that gall index is also a reliable criterion for rating resistance to $X$. index in longer tests (10-12 months) in order to identify $\mathrm{R}$ factors that should confer a more durable effect.

In our study, the distribution of the resistance levels to $X$. index was evaluated from $60 \mathrm{BC} 1$ individuals. The approximate 7R:1S segregation ratio obtained suggested that three dominant and independent resistance factors might be involved in the response to the nematode. To cope with this hypothesis, a method derived from the bulked-segregant analysis [35] and performed on SSRs revealed markers on LG 9, LG 10 and LG 18. A proportion test using both SSRs and SNPs identified markers in the same three LGs and therefore confirmed previous data.

The QTL analysis performed on the same individuals supported these findings since two QTLs were identified on LG 9 and LG 10. QTL location on LG10 was not clearly estimated on this chromosome since the LOD score distribution curve showed 3 significant peaks. A third QTL was detected on LG 18 and, even though it was not significant, its LOD score value was higher than those observed on other linkage groups. These 3 QTLs were officially named $X i R 2, X i R 3$ and $X i R 4$, according their location on LG9, LG10, LG18 respectively. These results provide the first location of resistance factors against the vector nematode $X$. index in muscadine. On the basis of segregation patterns observed in the progenies from Vitis crosses involving 13 species, one-gene and two-gene modes of tolerance to $X$. index were previously reported [48], and $\mathrm{Xu}$ et al. [22] identified a single resistance locus, XiR1, on the LG 19 of $V$. arizonica using a map from 185 plants. Interestingly, some hybrids, in particular the BC1 rootstock 'Nemadex Alain Bouquet', derived from the $M$. rotundifolia accession 'NC184-4' presently studied, were shown to decrease both $X$. index numbers and GFLV infection under greenhouse and field conditions [49-52]. Consequently, we hypothesize that resistance to $X$. index conferred by this muscadine accession will be associated with a delay in GFLV transmission by the nematode to the grapevine.

\section{QTLs identified for response to $D$. vitifoliaie and $X$. index map to chromosomic regions enriched in resistance gene analogs}

While $V$. vinifera is highly sensitive to the most critical pests and diseases for grapevine, wild Vitis and Muscadinia materials are characterized by various levels of resistance. Among all, powdery and downy mildew have been studied in details, and numerous loci controlling partial or total resistance to both diseases have been identified [53]. Interestingly, some of the chromosomal regions identified in our study as carrying $\mathrm{R}$ factors to $D$. vitifoliae and $X$. index already encompass QTLs identified in response to other major grapevine diseases. LG 18 contains many loci detected for resistance to downy mildew Plasmopara viticola and powdery mildew Erysiphe necator in mucadine [54, 55] or Vitis spp. [38, 5658]. Thus, among the markers flanking the Rpv3 (resistance to $P$. viticola) locus identified from 'Regent' genotype by van Heerden and collaborators [59] on LG 18, is the UDV-108 marker which has been identified in our study with the maximum LOD score in one of the three QTLs highlighted in response to $X$. index. Additionally, in Vitis spp., the loci $\operatorname{rpv} 7$ (resistance to downy mildew) and rpv5 and Ren 6 (downy and powdery mildew) have been reported on LG 7 and LG9 respectively [56, 60, 61]. These three chromosomes have been previously demonstrated to be enriched in NBS-LRR genes [62]. The current development of sequencing technologies should contribute to the comparison of Vitis genomes and to gather more precise knowledge about these resistance genes in order to use them in breeding new cultivars with multi-pest resistances.

\section{Conclusions}

With the objective of grapevine rootstock breeding, our data open the way to the use of muscadine as a source 
for the obligate phylloxera $\mathrm{R}$ feature and as an $\mathrm{R}$ source to $X$. index in order to delay GFLV transmission to grapevine by this nematode. In this work, we could successfully identify root resistances against phylloxera and $X$. index and map the first cognate QTLs from the $M$. rotundifolia source 'NC184-4'. Thus QTLs were identified on LG 7 completed by LG 3 and LG 10 in response to phylloxera and on LG 9, LG 10 and LG 18 in response to $X$. index. These newly identified trait-linked loci should now be tested in alternative crosses with $M$. rotundifolia. In the future, validated markers at those loci may allow their use in a marker-assisted breeding approach for producing new rootstocks with durable resistances.

\section{Methods}

\section{Plant material}

We used the backcross 1 ( $\mathrm{BC} 1$, population $\mathrm{Bdx} 0227$ ) segregating population of 135 individuals (Table S1) from the cross between the hybrid VRH8771 [('Cabernet-Sauvignon' $x$ 'Alicante Bouschet') $x$ M. rotundifolia cv. NC184-4] and $V$. vinifera cv. 'CabernetSauvignon' (VRH8771 x CS). This cross has been initiated by Alain Bouquet at INRAE Montpellier since 2005 and continued at INRAE UMR EGFV (Bordeaux, France) after 2008. The female parent VRH8771 was initially obtained from a cross made in 1975-1976 at INRAE Bordeaux with the intra-vinifera hybrid previously obtained in Bordeaux as the mother (accession number 8606), and pollen from Muscadine genotype NC184-4 obtained from Nesbitt W.B. (Raleigh, University of North Carolina, USA) [63]. VRH8771 is resistant to $D$. vitifoliae and $X$. index whereas $V$. vinifera 'Cabernet-Sauvignon' (CS), the male parent, is susceptible [49]. Parental genotypes and BC1 individuals are maintained at the INRAE germplasm repository (Bordeaux, France).

\section{Insect and nematode material}

For D. vitifoliae, all experiments were conducted with the isofemale clone 'Pcf7'. The original population was sampled in 2010 in a commercial vineyard at Pineuilh (Gironde, France) on V. vinifera cv. 'Cabernet franc' scions grafted on $\mathrm{SO} 4$ rootstock $(V$. berlandieri $x \mathrm{~V}$. riparia) and maintained at INRAE UMR SAVE (Bordeaux, France) on leaves of the American variety 'Harmony', a complex hybrid between Dog-Ridge ( $V$. champinii) and '1613C' ( $V$. labrusca $\times$ V. riparia $\times V$. vinifera) and on root pieces of $V$. vinifera cv. 'Cabernet Sauvignon', both genotypes originating from INRAE germplasm repository, multiplied as cuttings and grown under greenhouse conditions.

For $X$. index, all experiments were conducted with the isofemale line 'Frejus'. The original population has been sampled in a GFLV-infected grapevine field in Frejus (Provence, France). Using the population grown on grapevine in the greenhouse, the line had been created from a single female inoculated on a fig plant previously grown from in vitro.

\section{Experimental designs and phenotyping Phylloxera assays}

An in planta assay was performed with $89 \mathrm{BC} 1$ individuals. Two control genotypes were also tested: $V$. vinifera cv. 'Pinot Noir' and the rootstock 'Börner' (V. riparia $x$ $V$. cinerea) as susceptible and resistant genotypes respectively. This experiment was organized according to a randomized complete block design with three experimental blocks, each block being an independent randomization of one replicate of each $\mathrm{BC} 1$ individual. Plants were grown in individual pots of $1 \mathrm{~L}$ in a soil substrate composed of at least $50 \%$ clay with pebbles at the bottom to improve drainage. The soil was sterilized by autoclaving in order to prevent cross contamination with other phylloxera population sources. Each pot was covered with an insect-proof transparent plastic bell and an automatic watering system was adapted (Fig. S6 A). One hundred phylloxera eggs of 'Pcf7' clone, previously grown on root pieces of $V$. vinifera cv. 'Cabernet Sauvignon' for two generations, were deposited on a moistened and sterilized filter paper near the root $(\sim 3 \mathrm{~cm}$ depth) of each pot. Three months after inoculation, the plants were uprooted and the nodosity number was counted (Fig. S6 B). The maximal number of nodosities scored among the three replicates of each $\mathrm{BC} 1$ individual was considered as the most reliable indicator of the quantitative resistance phenotype.

An in vitro assay was also performed according to Pouget [64] to assess the larval development of phylloxera on $37 \mathrm{BC} 1$ individuals. Five woody root pieces per individual, 6 to $7 \mathrm{~cm}$ long, were arranged in small bundles (a contact between all the roots is required) on a disk of dampened blotting paper in a Petri dish sealed with parafilm. Three replicates were realized for each individual. A fungicide treatment (Ridomil Gold, Syngenta ${ }^{\circ}$ - $2.3 \mathrm{~g} / \mathrm{L}$ ) was carried out on the roots to prevent Botrytis cinerea infection. In each Petri dish, 50 phylloxera eggs were deposited on the roots pieces. Then Petri dishes were incubated at $25^{\circ} \mathrm{C}$ in the dark. The number of larvae that have developed on the five root pieces was counted 1 month after inoculation. The maximal number of larvae scored among the three replicates was considered as the best indicator of the quantitative resistance phenotype [12].

\section{$X$. index assays}

A total of $60 \mathrm{BC} 1$ individuals were evaluated during five successive experiments conducted between 2010 and 
2017 (Table S4). Three reference genotypes were also tested: the susceptible $V$. rupestris cv. 'du Lot', the resistant $\mathrm{BC} 1$ rootstock 'Nemadex Alain Bouquet' from the cross 'VRH8773 (V. vinifera $x M$. rotundifolia) x $140 \mathrm{Ru}$ ( $V$. berlandieri $x V$. rupestris)' and the susceptible to intermediate genotype 'VRH8624'. VRH8773 is a brother clone of VRH8771, and VRH8624 in an F1 hybrid ( $V$. vinifera $\times M$. rotundifolia) whose muscadine parent is the accession 'Trayshed' [65].

For each evaluation, homogenous hardwood cuttings of the individuals were rooted annually in alveolated plates in the nursery at INRAE UMR EGFV (Bordeaux, France) in February. In May, plants were delivered to INRAE UMR ISA (Sophia-Antipolis, France), planted individually into 2 -L pots with six replicates per individual and grown in a greenhouse. At the end of June, each pot was inoculated with a fixed number of nematodes that ranged from 300 to 900 depending on the year of experiment (Table S5). The plants were grown for ten to twelve months, which is the time that allows approximately three to four nematode developmental cycles over two successive calendar years.

At harvest, the aerial part of the plant was cut at the collar level and removed and each pot was hermitically placed into a plastic bag and stored in a cold chamber at $6{ }^{\circ} \mathrm{C}$. This stopped plant and nematode development simultaneously in all individual replicates until plant and nematode ratings. Ratings were done sequentially, i.e. replicate after replicate. Total soil of each 2-L pot was recovered in a 10-L bucket, over which plant roots were washed individually with caution under tap water. The entire root system of each plant was rated for its root development (RD) based on a 0-5 scale and its fresh root weight (RW) was also measured. Root galling was rated for each plant using a $0-5$ gall index (GI) scale derived from studies for resistance to the rootknot nematode Meloidogyne spp.: $0=$ no gall; $1=1-$ $10 \% ; 2=11-30 \% ; 3=31-70 \% ; 4=71-90 \% ; 5>90 \%$ of root system galled [66]. Nematodes of each plant were extracted from the total soil suspended in the bucket using an adapted Oostenbrink method [67]. In the two first experiments (2010-2011 and 2011-2012), final nematode numbers were counted under a binocular microscope. Then the ratio between nematode final and initial numbers was calculated to evaluate the mean nematode reproduction factor (RF) for each $\mathrm{BC} 1$ individual and the parental and reference genotypes. Individuals were classified as resistant (R) when their $R F$ value was lower than 1 and susceptible $(S)$ when their RF value was equal or above 1 . As the two first experiments showed that RF ratings were significantly correlated with GI ratings (see Results section), no nematode extraction was performed for the three last experiments (2012-2013, 2015-2016 and 2016-2017) and individuals were classified directly as $\mathrm{R}$ or $\mathrm{S}$ from their visual symptoms.

\section{Treatment of phenotypic data sets Phylloxera assays}

The number of nodosities and the number of larvae were explored using the following generalized mixed model:

$$
\mathrm{P}_{\mathrm{ij}}=\mu+\text { individual } \text { block }_{\mathrm{j}}+\varepsilon_{\mathrm{ij}}
$$

where $P_{i j}$ is the observed phenotype, $\mu$ is the overall mean of the phenotypic data, 'individual' corresponds to the genetic differences among the $\mathrm{BC} 1$ individuals, 'block' accounts for the differences in microenvironmental conditions among the three blocks, and $\varepsilon_{i j}$ is the residual term ( $\mathrm{R}_{\text {LME4 }}$ package). The factor 'individual' was treated as a random factor, whereas the factor 'block' was treated as a fixed factor. The 'Best linear unbiased predictions' (BLUP) of random effects were extracted from the selected generalized mixed model. The BLUP values were noted by the name of the trait preceded by the word BLUP.

For each quantitative phenotypic trait, broad sense heritability was estimated using the formula $h^{2}=\sigma_{g}^{2} /$ $\left[\sigma_{g}^{2}+\sigma_{e / n}^{2}\right]$, where $\sigma_{g}^{2}$ is the genetic variance, $\sigma_{e}^{2}$ is the environmental variance and $n$ is the number of plants per accession.

\section{Nematode assays}

All principal component analyses (PCA) and parametric and non-parametric statistical tests were performed using $\mathrm{R}$ version 3.4.0. Statistical significance was set at $P<0.05$.

\section{Mapping of the resistance traits Simple sequence repeats (SSR) markers}

DNA was extracted from 50 to $100 \mathrm{mg}$ of young leaves grown in a greenhouse from $90 \mathrm{BC} 1$ individuals (Table $\mathrm{S} 1)$. Leaves were ground in $5 \mathrm{~mL}$ of a first buffer extraction containing sodium metabisulfite [sodium metabisulfite $20 \mathrm{mM}$, Tris- $\mathrm{HCl} \mathrm{pH} 80.2 \mathrm{M}$, EDTA pH $870 \mathrm{mM}$, $\mathrm{NaCl} 2 \mathrm{M}$ ]. $500 \mu \mathrm{L}$ of this homogenate was incubated with $450 \mu \mathrm{L}$ of a second buffer with CTAB [CTAB $2 \%$, $\mathrm{NaCl} 1.4 \mathrm{M}$, EDTA pH 820 mM, Tris- $\mathrm{HCl}$ pH $80.1 \mathrm{M}$ ] during $1 \mathrm{~h}$ at $65^{\circ} \mathrm{C}$. Then the solution was centrifuged for $30 \mathrm{~min}$ at $13,000 \mathrm{rpm}$ at $4{ }^{\circ} \mathrm{C} .500 \mu \mathrm{L}$ of supernatant was sampled and cleaned with the same volume of a solvent chloroforme:octanol (24:1). After $20 \mathrm{~min}$ of spin at $13,000 \mathrm{rpm}$ at $4{ }^{\circ} \mathrm{C}$, we recovered $300 \mu \mathrm{L}$ of the aqueous phase in $450 \mu \mathrm{L}$ of a solution of isopropanol: ammonium acetate $(2: 1)$. We left $1 \mathrm{~h}$ at $4{ }^{\circ} \mathrm{C}$ and then we centrifuged at $13,000 \mathrm{rpm}$ for $20 \mathrm{~min}$ at $4{ }^{\circ} \mathrm{C}$. We discarded the solution and washed the pellet with $70 \%$ 
ethanol v/v (two times). After centrifugation (13,000 rpm for $20 \mathrm{~min}$ at $4{ }^{\circ} \mathrm{C}$ ), we discarded the ethanol, and precipitated the pellet in 100 to $200 \mu \mathrm{L}$ of TE $0.1 \mathrm{X}$ [Tris $\mathrm{HCl} 10 \mathrm{mM}$, EDTA $1 \mathrm{mM}$ ]. DNAs were quantified by Nanodrop ${ }^{\mathrm{Tu}}$.

A total of 217 primers pairs were used: $61 \mathrm{VMC}$ (Vitis Microsatellite Consortium, managed through AGROGENE, Moissy Cramayel, France), 7 VVMD [68], 1 VVS [69], 6 SC08 [70], 1 VrZAG [71], 7 VVC [69], 59 VVI [72], 11 MRBX [73], 21 UDV [74] and marker Gf13-9 [12]. Two new series of SSRs, VVBX and VVBX-A, were designed from the genome $12 \mathrm{X}$ of $V$. vinifera $\mathrm{cv}$. 'Pinot Noir' (PN40024) using Primer3 software [75]. Primers characteristics of VVBX and VVBX-A markers are reported in Table S6.

PCRs were performed by a single reaction with M13tailed forward primer [76] conjugated with four different dyes $\left(6 \mathrm{FAM}^{\mathrm{sm}}, \mathrm{VIC}^{\oplus}, \mathrm{NED}^{\mathrm{m}}\right.$ and $\left.\mathrm{PET}^{\circ}\right)$ in $15 \mu$ reaction volume containing: $5 \mathrm{ng}$ of DNA template, $1.5 \mu \mathrm{L}$ of 10xPCR reaction buffer, $2 \mathrm{mM}$ of $\mathrm{MgCl} 2,0.2 \mathrm{mM}$ of each dNTP, $0.05 \mu \mathrm{M}$ of M13 tailed SSR forward primer, $0.2 \mu \mathrm{M}$ of reverse primer, $0.2 \mu \mathrm{M}$ of dye conjugated with M13 primer, and $0.2 \mathrm{U}$ of JumpStart ${ }^{\mathrm{m}}$ Taq DNA Polymerase (Sigma-Aldrich). Amplification conditions were as follows: $5 \mathrm{~min}$ initial denaturation step at $95^{\circ} \mathrm{C}$ followed by 2 cycles $\left(30 \mathrm{~s}\right.$ denaturation at $95^{\circ} \mathrm{C}, 1.5 \mathrm{~min}$ annealing at $60^{\circ} \mathrm{C}$ or $56^{\circ} \mathrm{C}$ and $1 \mathrm{~min}$ extension at $72^{\circ} \mathrm{C}$ ) followed by 35 cycles $\left(30 \mathrm{~s}\right.$ denaturation at $95^{\circ} \mathrm{C}, 30 \mathrm{~s}$ annealing at $60^{\circ} \mathrm{C}$ or $56^{\circ} \mathrm{C}$ and $1 \mathrm{~min}$ extension at $72^{\circ} \mathrm{C}$ ) then followed by $10 \mathrm{~min}$ final extension at $72^{\circ} \mathrm{C}$. Visualization was performed by a 3730 DNA analyzer (Applied Biosystem ${ }^{\mathrm{nt}}$ ). Eight to sixteen PCR products were pooled, according to the size of SSRs and the dyes, and analyzed in a single run. Electropherograms were analyzed using free software STRand. Any ambiguous genotypes were re-run, re-amplified or left as unknown.

\section{Single nucleotide polymorphisms (SNP) markers}

Two foliar disks ( $1.5 \mathrm{~cm}$ of diameter) of $128 \mathrm{BC} 1$ individuals grown in a greenhouse were sampled (Table S1). DNA extractions were realized on dried leaf tissues using the same protocol as described by Cormier et al. [77]. Genotyping-by-sequencing (GBS) was performed as described by Elshire et al. [32] (Keygene N.V. owns patents and patent applications protecting its Sequence Based Genotyping technologies) integrating two 96-well plates across 96 barcodes for library preparation. The genomic library was prepared using ApeKI restriction enzyme. Paired-end sequencing of $150 \mathrm{bp}$ reads was performed on an Illumina HiSeq3000 system (at the GeTPlaGe platform in Toulouse, France).

Raw reads were checked with FastQC [78], demultiplexed with a custom script (https://github.com/timflutre) and cleaned with CutAdapt [79]. Cleaned reads were then mapped to the $V$. vinifera cv 'Pinot Noir' (PN40024) genome assemblies for SNP calling. Alignment on this genome was performed using BurrowsWheeler Aligner maximal exact match (BWA-MEM) with default parameters [80], SAMtools and Picard (http://broadinstitute.github.io/picard/). SNP calling was performed with GATK using the hardfilter parameters [81-83].

VCFtools was used to remove SNPs with a quality score $<200$ and with depth values $<10$ [84]. Qualityfiltered SNPs were analyzed with the major_minor and get_pseudo_test_cross scripts from HetMappS pipeline to identify pseudo-testcross markers [85]. In the variant call format (VCF) output file only sites with less than $10 \%$ missing data were retained. Individuals with more than $50 \%$ missing data and those with genotype frequencies different from expected 1:1 marker segregation were discarded. Two sets of markers were obtained corresponding to the two parental genotypes.

\section{Map construction}

Individual maps were constructed for each parental genotype following a double pseudo-testcross strategy [86]. Marker segregation was analysed with regard to goodness-of-fit to the expected Mendelian ratio using the Chi-square test $(P<0.05)$. Marker types of $l m x l l$ and $n n \times n p$ were retained for construction of maternal and paternal maps, respectively. Genetic maps and marker order were determined using the maximum likelihood (ML) algorithm with Haldane function and default parameters of JoinMap ${ }^{\circ} 4.1$ software $[87,88]$. Linkage groups (LGs) were constructed with a minimum threshold logarithm of odds (LOD) score of 6.0. LGs were grouped and numbered based on their corresponding physical chromosome numbers [41].

\section{Methods for resistance mapping Phylloxera assays}

The maximum number of nodosities (in planta assay), the maximum number of larvae (in vitro assay) and the BLUP values associated were used as the quantitative scores of susceptibility/resistance response.

Detection of quantitative trait loci (QTLs) was performed with the one-dimension scan function, scanone, of R/qtl software using a normal model but also a nonparametric analysis and the expectation-maximization (EM) algorithm method depending on the normality of the data $[88,89]$. Multipoint genotype probabilities were calculated beforehand using calc.genoprob with step $=1$ and default parameters. Logarithm of odd score (LOD) significance threshold was estimated with 1000 permutations and for a significant level $\alpha$ of 0.05 . An interval estimate of the location of each QTL was calculated using the 1.5-LOD intervals method of Rqtl [90]. The 
percentage of the phenotypic variation explained by a QTL corresponds to the regression value $R^{2}$ taken at its peak LOD score.

\section{Nematode assays}

Based on SSR markers, an in silico method derived from the Bulked Segregant Analysis (BSA) was performed [35]. In the VRH8771 x CS progeny, polymorphic markers were distributed into either $2(\mathrm{ab}), 3(\mathrm{abc})$ or 4 (abcd) allelic forms. From each of the markers screened, markers retained were those for which an allele was detected in the resistant parent (VRH8771) and in part of the resistant $\mathrm{BC} 1$ individuals but in none of all susceptible $\mathrm{BC} 1$ individuals.

The resistant and susceptible phenotypes were converted to values equal to 0 and 1 , respectively. The onedimension scan function, scanone, of R/qtl software was performed with the argument model= 'binary' [90]. LOD significance threshold, the QTL interval and the $R^{2}$ value were obtained with the procedure described in the previous paragraph. A number of 47 phenotyped individuals were used for the BSA analysis with SSR markers whereas the 60 total individuals phenotyped were used for QTL analysis with SSR and SNP markers.

\section{Supplementary information}

Supplementary information accompanies this paper at https://doi.org/10 1186/s12870-020-2310-0.

Additional file 1: Table S1. Characteristics of the $135 \mathrm{BC} 1$ individuals. Table S2. Statistical analyzes comparing data between 2010 and 2011 and 2011-2012 experiments. Table S3. Spearman correlations of the four criteria (RD - RW - RF - Gl) in response to X. index. Table S4. Results of the proportion test performed on $60 \mathrm{BC} 1$ individuals in response to $X$. index. Table S5. Characteristics of the experiments in response to $X$. index carried out over five independent years. Table S6. Primers characteristics.

Additional file 2: Figure S1. Maternal genetic map related to VRH8771. Figure S2. Paternal genetic map related to CS. Figure S3. Variation of genetic distance depending on physical distance on the VRH8771 (A) and CS (B) genetic maps. Figure S4. Principal component analysis (PCA) of the 35 F1 individuals tested in 2010-2011 and 2011-2012 experiments with root system development (RD), root weight (RW), nematode reproduction factor (RF) and gall index (GI). Figure S5. QTL analysis of the resistance to $X$. index performed on $60 \mathrm{BC} 1$ individuals. The results of the analysis performed on LG 9 and LG 10 are presented. The $y$-axis represents the LOD score obtained by the binary mapping and the $x$-axis represents the 19 linkage groups related to the maternal genetic map (VRH8771). Curves in plot indicate the genetic coordinate (x-axis) and LOD score (y-axis). The red dotted line represents the LOD significant threshold estimated with 1000 permutations for a level a of 0.05 . Figure S6. In planta experiment (A) illustration of the experimental device with each plant grown in an individual pot covered by a transparent plastic bell and (B) example of nodosities developed on roots (red arrows).

\section{Abbreviations}

BLUP: Best linear unbiased predictions; BSA: Bulked segregant analysis; EM: Expectation-maximization; GBS: Genotyping-by-sequencing; LG: Linkage group; LOD: Logarithm of odds ratio; ML: maximum likelihood; NGS: Nextgeneration sequencing; PCA: Principal component analysis; QTL: Quantitative trait locus; SNP: Single nucleotide polymorphism; VCF: Variant call format

\section{Acknowledgements}

This manuscript is dedicated to Alain Bouquet who initiated numerous crosses involving muscadine in particular the cross used in this study. Without him, nothing would have been possible. The authors thank A. El Msayryb and A. Bakhkhouch for their help in nematological analyses, B. Douens, J-P Robert and C. Hévin for their contribution to plant material multiplication and maintenance, and N. Girollet for his wise advices and help in bioinformatic processing of data.

\section{Authors' contributions}

NO, DE and DP designed the study. ML and J-PT performed the crosses and participated to the maintenance of the progeny. $M L, J-P P, B J$ and DP performed the phylloxera tests and ML, MD, BJ, DP, GLT and BR analyzed the data for phylloxera. DE, RV, UP and CVG performed the $X$. index tests and DE, GLT and BR analyzed the data for $X$. index. GLT and MD collected the samples for DNA extraction and performed microsatellite genotyping. GLT, LLC and BR constructed the genetic maps and performed the statistical analysis. GLT and BR contributed to the QTL analyses. P-FB aided in interpreting the results and contributed to the correction of the manuscript. DE, GLT and BR wrote the first version of the manuscript. DE, BR, LLC and NO generated the last version of the manuscript. All authors read and approved the manuscript

\section{Funding}

This study has received funding from the European Union's Seventh framework program for research, technological development and demonstration under grant agreement n³11775 (Innovine, 2013-2016) which supported the SSR genotyping of the population, the establishment of the SSR map, the phylloxera assays and GLT initial contract. It was also partly funded by the French Ministry of Agriculture through the CASDAR contracts 'RemuneX' (2015-2018) (CTPS Project $\left.n^{\circ} \mathrm{C}-2014-09\right)$, for the nematode assays, the completion of the SSR map, the BSA analysis and GLT contract. 'PIVERT I and II' (2016-2019) (France AgriMer EDP 0916002775 EDP 091700 3392, EDP 091800 3764) contributed to the GBS for the population, the establishment of the SNP map, the QTL detection, GLT final contract and BR contract. A complementary funding has been provided by the contracts INRA-AgriObtentions IVD3 (2011-2015) and IVD4 (2016-2020) for phenotyping activities, SSR and SNP genotyping.

\section{Availability of data and materials}

The data sets during the current study are available from the corresponding author.

Ethics approval and consent to participate

Not applicable.

\section{Consent for publication}

Not applicable.

\section{Competing interests}

The authors declare that they have no competing interests.

\section{Author details}

${ }^{1}$ INRAE, UMR EGFV, 33883 Villenave d'Ornon, France. ${ }^{2}$ IFV, Domaine de I'Espiguette, 30240 Le Grau du Roi, France. ${ }^{3}$ INRAE, Université Nice Côte d'Azur, CNRS, ISA, 06903 Sophia Antipolis, France. ${ }^{4}$ INRAE, UMR SAVE, 33883 Villenave d'Ornon, France.

Received: 6 September 2019 Accepted: 26 February 2020

Published online: 12 May 2020

References

1. This P, Lacombe T, Thomas MR. Historical origins and genetic diversity of wine grapes. Trends Genet. 2006;22:511-9.

2. Pouget R. Histoire de la lutte contre le phylloxéra de la vigne en France. Paris: INRA/OIV; 1990. p. 157

3. Thiéry D, Vogelweith F. La colocation en vigne : interactions entre plante, les insectes ravageurs et leurs parasitoïdes. La Garance Voyageuse. 2016;113: 19-25.

4. Powell KS. A holistic approach to future management of grapevine phylloxera. In: Bostanian NJ, Vincent C, Isaacs R, editors. Arthropods 
Management in Vineyards: Pests, approaches, and future directions; 2012. p. 219-51.

5. Smith HM, Clarke CW, Smith BP, et al. Genetic identification of SNP markers linked to a new grape phylloxera resistant locus in Vitis cinerea for markerassisted selection. BMC Plant Biol. 2018;18:360.

6. Powell KS. Grape Phylloxera : An Overview. In: Johnson SN, Murray GM, editors. Root feeders : An ecosystem perspective: CAB International; 2008. p. 96-114.

7. Boubals $D$. Hérédité de la résistance au phylloxéra radicicole chez la vigne. Ann Amélioration Plantes. 1966;16:327-47.

8. Davidis UX, Olmo HP. The Vitis vinifera $\times$ V. rotundifolia Hybrids as phylloxera resistant rootstocks. Vitis. 1964;4:129-43.

9. Ramming DW. Greenhouse screening of grape rootstock populations to determine inheritance of resistance to phylloxera. Am J Enol Vitic. 2010;61: 234-9.

10. Bouquet A. Etude de la résistance au phylloxéra radicicole des hybrides Vitis vinifera $\times$ Muscadinia rotundifolia. Vitis. 1983;22:311-23.

11. Roush TL, Granett J, Walker MA. Inheritance of gall formation relative to phylloxera resistance levels in hybrid grapevines. Am J Enol Vitic. 2007;58: 234-41.

12. Zhang J, Hausmann $L$, Eibach $R$, et al. A framework map from grapevine V3125 (Vitis vinifera 'Schiava grossa' × 'Riesling') × rootstock cultivar 'Börner' (Vitis riparia $\times$ Vitis cinerea) to localize genetic determinants of phylloxera root resistance. Theor Appl Genet. 2009;119:1039-51.

13. Clark MD, Teh SL, Burkness E, et al. Quantitative trait loci identified for foliar phylloxera resistance in a hybrid grape population: Foliar phylloxera resistance. Aust J Grape Wine Res. 2018;24:292-300.

14. Andret-Link P, Laporte C, Valat L, et al. Grapevine fanleaf virus: still a major threat to the grapevine industry. J Plant Pathol. 2004;86:183-95.

15. Hewitt WB, Raski DJ, Goheen AC. Nematode vector of soil-borne fanleaf virus of grapevines. Phytopathology. 1958;48:586-95.

16. Demangeat $\mathrm{G}$, Esmenjaud $\mathrm{D}$, Voisin $\mathrm{R}$, et al. Le court-noué de la vigne. Phytoma - La défense des végétaux. 2005;587:38-42.

17. Esmenjaud D, Walter B, Valentin G, et al. Vertical distribution and infectious potential of Xiphinema index (Thorne et Allen, 1950) (Nematoda : Longidoridae) in fields affected by grapevine fanleaf virus in vineyards in the Champagne region of France. Agronomie. 1992;12:395-9.

18. Villate $L$, Fievet $V$, Hanse $B$, et al. Spatial distribution of the dagger nematode Xiphinema index and its associated Grapevine fanleaf virus in French vineyard. Phytopathology. 2008:98:942-8.

19. Esmenjaud D, Bouquet A. Selection and application of resistant germplasm for grapevine nematodes management. In: Ciancio A, Mukerji KG, editors. Integrated Management of Fruit Crops and Forest Nematodes: Springer Science+Business Media B.V; 2009. p. 195-214.

20. Ollat N, Peccoux A, Papura D, et al. Rootstocks as a component of adaptation to environment. In: Gerós HV, Chaves MM, Gil HM, Delrot S, editors. Grapevine in a Changing Environment: A Molecular and Ecophysiological Perspective. Chichester: Wiley Blackwell; 2016. p. 68-108,

21. Riaz S, Hu R, Walker MA. A framework genetic map of Muscadinia rotundifolia. Theor Appl Genet. 2012;125:1195-210.

22. Xu K, Riaz S, Roncoroni NC, et al. Genetic and QTL analysis of resistance to Xiphinema index in a grapevine cross. Theor Appl Genet. 2008;116:305-11.

23. Töpfer R, Hausmann L, Harst M, et al (2011) New horizons for grapevine breeding. In: Flachowsky H., Hanke M.-V (eds) Methods Temperate Fruit Breed pp 79-100

24. Riaz S, Pap D, Uretsky J, Laucou V, Boursiquot J-M, Kocsis L, Andrew Walker M. Genetic diversity and parentage analysis of grape rootstocks. Theor Appl Genet. 2019. https://doi.org/10.1007/s00122-019-03320-5.

25. Walker MA, Wolpert JA, Weber E. Viticultural characteristics of VR hybrid rootstocks in a vineyard site infected with Grapevine fanleaf virus. Vitis. 1994;33:19-23.

26. Bouquet A. Vitis $\times$ Muscadinia hybridization: A new way in grape breeding for disease resistance in France. Proc Third Intl Symp Grape Breed. 1980:42-61.

27. Varshney RK, Nayak SN, May GD, Jackson SA. Next-generation sequencing technologies and their implications for crop genetics and breeding. Trends Biotechnol. 2009;27:522-30

28. Doligez A, Adam-Blondon AF, Cipriani G, et al. An integrated SSR map of grapevine based on five mapping populations. Theor Appl Genet. 2006;113: 369-82.

29. Troggio M, Malacarne G, Coppola G, et al. A dense single-nucleotide polymorphism-based genetic linkage map of grapevine (Vitis vinifera L.) anchoring Pinot Noir bacterial artificial chromosome contigs. Genetics. 2007; 176:2637-50.

30. Ray S, Satya P. Next generation sequencing technologies for next generation plant breeding. Front Plant Sci. 2014;5:1-4.

31. Vlk D, Řepková J. Application of next-generation sequencing in plant breeding. Czech J Genet Plant Breed. 2017;53:89-96.

32. Elshire RJ, Glaubitz JC, Sun Q, et al. A Robust, Simple Genotyping-bySequencing (GBS) Approach for High Diversity Species. PLoS One. 2011;6(5): e19379

33. Poland JA, Rife TW. Genotyping-by-Sequencing for Plant Breeding and Genetics. Plant Genome. 2012;5:92-102.

34. Barba P, Cadle-Davidson L, Harriman J, et al. Grapevine powdery mildew resistance and susceptibility loci identified on a high-resolution SNP map. Theor Appl Genet. 2014;127:73-84.

35. Michelmore RW, Paran I, Kesseli RV. Identification of markers linked to disease-resistance genes by bulked segregant analysis: a rapid method to detect markers in specific genomic regions by using segregating populations. Proc Natl Acad Sci. 1991;88:9828-32.

36. Adam-Blondon A-F, Roux C, Claux D, et al. Mapping 245 SSR markers on the Vitis vinifera genome: a tool for grape genetics. Theor Appl Genet. 2004;109: $1017-27$.

37. Wang $\mathrm{N}$, Fang $\mathrm{L}$, Xin $\mathrm{H}$, et al. Construction of a high-density genetic map for grape using next generation restriction-site associated DNA sequencing. BMC Plant Biol. 2012;12:148.

38. Sapkota S, Chen L, Yang S, et al. Construction of a high-density linkage map and QTL detection of downy mildew resistance in Vitis aestivalis-derived 'Norton'. Theor Appl Genet. 2019;132:137-47.

39. Teh S-L, Fresnedo-Ramirez J, Clark MD, et al. Genetic dissection of powdery mildew resistance in interspecific half-sib grapevine families using SNP-based maps. Mol Breed. 2017;37:1. https://doi.org/10.1007/s11032-016-0586-4.

40. Adam-Blondon AF, Martinez-Zapater JM, Kole C. Genetics, Genomics, and Breeding of Grapes: Science Publishers and CRC Press Book; 2011.

41. The French-Italian Public Consortium for Grapevine Genome Characterization. The grapevine genome sequence suggests ancestral hexaploidization in major angiosperm phyla. Nature. 2007;449:463-7.

42. Delame $M$, Prado $E$, Blanc $S$, et al. Introgression reshapes recombination distribution in grapevine interspecific hybrids. Theor Appl Genet. 2019;132 1073-87.

43. Blanc S, Wiedemann-Merdinoglu S, Dumas V, et al. A reference genetic map of Muscadinia rotundifolia and identification of Ren5, a new major locus for resistance to grapevine powdery mildew. Theor Appl Genet. 2012;125:166375.

44. Piepho HP, Möhring J, Melchinger AE, Büchse A. BLUP for phenotypic selection in plant breeding and variety testing. Euphytica. 2008;161:209-28.

45. Sadok IB, Celton J-M, Essalouh L, et al. QTL mapping of flowering and fruiting traits in olive. PLoS One. 2013;8:e62831.

46. Segura V, Durel C-E, Costes E. Dissecting apple tree architecture into genetic, ontogenetic and environmental effects: QTL mapping. Tree Genet Genomes. 2009:5:165-79.

47. Hwang C-F, Xu K, Hu R, et al. Cloning and characterization of XiRT, a locus responsible for dagger nematode resistance in grape. Theor Appl Genet. 2010;121:789-99.

48. Meredith CP, Lider LA, Raski DJ, Ferrari NL. Inheritance of tolerance to Xiphinema index in Vitis species. Am J Enol Vitic. 1982;33:154-8.

49. Bouquet $A$, Danglot $Y$, Bongiovanni $M$, et al. Breeding rootstocks resistance to Grape fanleaf virus spread, using Vitis $\times$ Muscadinia hybridization. Acta Hortic. 2000;528:517-26.

50. Claverie M, Audeguin L, Barbeau G, et al. Nemadex AB : Bilan des réseaux d'expérimentation en France. Progrès Agricole et Viticole. 2016:17-29.

51. Nguyen VC. Genetic diversity of the grapevine vector nematode Xiphinema index and application to optimize the resistance strategy. In: Doctoral dissertation, Université Côte d'Azur; 2018. p. 179

52. Ollat N, Claverie M, Esmenjaud D, et al. Nemadex Alain Bouquet : un nouveau porte-greffe contrôlant la recontamination des vignes par la maladie du court-noué. Phytoma. La Défense des Végétaux. 2011;649:29-33.

53. Merdinoglu D, Scneider $C$, Prado $E$, et al. Breeding for durable resistance to downy and powdery mildew in grapevine. OENO one. 2018;52:203-9.

54. Riaz S, Tenscher AC, Ramming DW, Walker MA. Using a limited mapping strategy to identify major QTLs for resistance to grapevine powdery mildew (Erysiphe necator) and their use in marker-assisted breeding. Theor Appl Genet. 2011;122:1059-73. 
55. Wiedemann-Merdinoglu S, Prado E, Coste P, et al. Genetic analysis of resistance to downy mildew from Muscadinia rotundifolia. In: 9th International conference on Grape Genetics and Breeding. Udine; 2006.

56. Bellin D, Peressotti E, Merdinoglu D, et al. Resistance to Plasmopara viticola in grapevine 'Bianca' is controlled by a major dominant gene causing localised necrosis at the infection site. Theor Appl Genet. 2009;120:163-76.

57. Welter LJ, Göktürk-Baydar N, Akkurt M, et al. Genetic mapping and localization of quantitative trait loci affecting fungal disease resistance and leaf morphology in grapevine (Vitis vinifera L). Mol Breed. 2007;20:359-74.

58. Zyprian E, Ochßner I, Schwander F, et al. Quantitative trait loci affecting pathogen resistance and ripening of grapevines. Mol Gen Genomics. 2016; 291:1573-94.

59. van Heerden CJ, Burger P, Vermeulen A, Prins R. Detection of downy and powdery mildew resistance QTL in a 'Regent' x 'RedGlobe' population. Euphytica. 2014:200:281-95.

60. Marguerit E, Boury C, Manicki A, et al. Genetic dissection of sex determinism, inflorescence morphology and downy mildew resistance in grapevine. Theor Appl Genet. 2009;118:1261-78.

61. Pap D, Riaz S, Dry IB, et al. Identification of two novel powdery mildew resistance loci, Ren6 and Ren7, from the wild Chinese grape species Vitis piasezkii. BMC Plant Biol. 2016;16:170.

62. Di Gaspero G, Cipriani G, Adam Blondon AF, Testolin R. Linkage maps of grapevine displaying the chromosomal locations of 420 microsatellite markers and 82 markers for R-gene candidates. Theor Appl Genet. 2007;114: 1249-63. https://doi.org/10.1007/s00122-007-0516-2.

63. Bouquet $\mathrm{A}$. Contribution à l'étude de l'espèce Muscadinia rotundifolia (Michx) Small et de ses hybrides avec Vitis vinifera L. In: Applications en sélection: Thèse de I'Université de Bordeaux II; 1983. p. 207.

64. Pouget $R$. Méthode de contamination de racines de vigne in vitro par le phylloxéra radicicole: application à la recherche de porte-greffes résistants. Connaiss. Vigne Vin. 1975;9:165-76.

65. Esmenjaud D, Decrooca S, Bouquet A, Ollat N. Host Suitability of Vitis and Vitis-Muscadinia material to the nematode Xiphinema index over one to four years. Am J Enol Vitic. 2010;61:96-101.

66. Barker KR. Design of greenhouse and microplot experiments for evaluation of plant resistance to nematodes. In: Zuckerman BM, MAi WS, Harrison MB, editors. Plant Nematology Laboratory Manual. Amherst: University of Massachussets Agriculture Experiment Station; 1985. p. 103-13.

67. De Goede RGM, Verschoor B. The nematode extraction efficiency of the Oostenbrink elutriator-cottonwool filter method with special reference to nematode body size and life strategy. Nematology. 2000;2:325-42.

68. Bowers JE, Dangl GS, Meredith CP. Development and characterization of additional microsatellite DNA markers for grape. Am J Enol Vitic. 1999;50: 243-6.

69. Thomas MR, Scott NS. Microsatellite repeats in grapevine reveal DNA polymorphisms when analyzed as sequence-tagged sites (STSs). Theor Appl Genet. 1993:86:985-90

70. Cipriani G, Di Gaspero G, Canaguier A, et al. Molecular linkage maps: strategies, resources and achievements. In: Adam-Blondon AF, MartinezZapater JM, Kole C, editors. Genet Genomics Breed Grapes; 2011. p. 111-36.

71. Sefc KM, Regner F, Turetschek E, et al. Identification of microsatellite sequences in Vitis riparia and their applicability for genotyping of different Vitis species. Genome. 1999:42:367-73.

72. Merdinoglu D, Butterlin G, Bevilacqua L, et al. Development and characterization of a large set of microsatellite markers in grapevine (Vitis vinifera L.) suitable for multiplex PCR. Mol Breed. 2005;15:349-66.

73. Zah-Bi I, Blanc S, Bras M, et al. Development of resources for comparative physical mapping between Muscadinia rotundifolia and Vitis vinifera. In: Proceedings of the 6th International Workshop of Grapevine Downy and Powdery Mildew. GDPM 2010. Villenave d'Ornon; 2010.

74. Di Gaspero G, Cipriani G, Marrazzo MT, et al. Isolation of (AC) nmicrosatellites in Vitis vinifera $\mathrm{L}$. and analysis of genetic background in grapevines under marker assisted selection. Mol Breed. 2005;15:11-20.

75. Untergasser A, Cutcutache I, Koressaar T, et al. Primer3-new capabilities and interfaces. Nucleic Acids Res. 2012;40:e115.

76. Oetting WS, Lee HK, Flanders DJ, et al. Linkage analysis with multiplexed short tandem repeat polymorphisms using infrared fluorescence and M13 tailed primers. Genomics. 1995;30:450-8.

77. Cormier F, Lawac F, Maledon E, et al. A reference high-density genetic map of greater yam (Dioscorea alata L.). Theor Appl Genet. 2019. https://doi.org/ 10.1007/s00122-019-03311-6.
78. Andrews S. FastQC: a quality control tool for high throughput sequence data. 2016. http://www.bioinformatics.babraham.ac.uk/projects/fastqc.

79. Martin M. Cutadapt removes adapter sequences from high-throughput sequencing reads. EMBnet J. 2011;17:10-2.

80. Li H, Durbin R. Fast and accurate short read alignment with BurrowsWheeler transform. Bioinformatics. 2009;25:1754-60.

81. DePristo MA, Banks E, Poplin R, et al. A framework for variation discovery and genotyping using next-generation DNA sequencing data. Nat Genet. 2011:43:491-8.

82. McKenna A, Hanna M, Banks E, et al. The Genome Analysis Toolkit: A MapReduce framework for analyzing next-generation DNA sequencing data. Genome Res. 2010;20:1297-303.

83. van der Auwera GA, Carneiro MO, Hartl C, et al. From FastQ Data to HighConfidence Variant Calls: The Genome Analysis Toolkit Best Practices Pipeline: The Genome Analysis Toolkit Best Practices Pipeline. In: Bateman A Pearson WR, Stein LD, et al., editors. Current Protocols in Bioinformatics: John Wiley \& Sons; 2013. p. 11.10.1-11.10.33.

84. Danecek P, Auton A, Abecasis $G$, et al. The variant call format and VCFtools. Bioinformatics. 2011;27:2156-8.

85. Hyma KE, Barba P, Wang M, et al. Heterozygous Mapping Strategy (HetMappS) for High Resolution Genotyping-By-Sequencing Markers: A Case Study in Grapevine. PLoS One. 2015;10:e0134880.

86. Grattapaglia D, Sederoff R. Genetic linkage maps of Eucalyptus grandis and Eucalyptus urophylla using a pseudo-testcross: mapping strategy and RAPD markers. Genetics. 1994;137:1121-37.

87. van Ooijen. JoinMap4, software for the calculation of genetic linkage maps in experimental populations. Wageningen: Kyazma BV; 2006.

88. Broman KW, Wu H, Sen S, Churchill GA. R/qtl: QTL mapping in experimental crosses. Bioinformatics. 2003;19:889-90.

89. Dempster AP, Laird NM, Rubin DB. Maximum Likelihood from Incomplete Data Via the EM Algorithm. J R Stat Soc Ser B Methodol. 1977;39:1-22.

90. Broman KW, Sen S. A guide to QTL mapping with R/qtl. Dordrecht: Springer; 2009.

\section{Publisher's Note}

Springer Nature remains neutral with regard to jurisdictional claims in published maps and institutional affiliations.

\section{Ready to submit your research? Choose BMC and benefit from:}

- fast, convenient online submission

- thorough peer review by experienced researchers in your field

- rapid publication on acceptance

- support for research data, including large and complex data types

- gold Open Access which fosters wider collaboration and increased citations

- maximum visibility for your research: over $100 \mathrm{M}$ website views per year

At BMC, research is always in progress.

Learn more biomedcentral.com/submissions 